Duarte, A., J. E. Hines, J. D. Nichols, J. S. Hatfield, and F. W. Weckerly. 2014. Age-specific survival of male Golden-cheeked Warblers on the Fort Hood Military Reservation, Texas. Avian Conservation and Ecology 9(2): 4. http://dx.doi.org/10.5751/ACE-00693-090204

Copyright (C) 2014 by the author(s). Published here under license by the Resilience Alliance.

Research Paper

\title{
Age-specific survival of male Golden-cheeked Warblers on the Fort Hood Military Reservation, Texas
}

\author{
Adam Duarte ${ }^{1}$, James E. Hines ${ }^{2}$, James D. Nichols ${ }^{2}$, Jeff S. Hatfield ${ }^{2}$ and Floyd W. Weckerly ${ }^{1}$ \\ ${ }^{1}$ Department of Biology, Texas State University, ${ }^{2}$ U.S. Geological Survey Patuxent Wildlife Research Center
}

\begin{abstract}
Population models are essential components of large-scale conservation and management plans for the federally endangered Golden-cheeked Warbler (Setophaga chrysoparia; hereafter GCWA). However, existing models are based on vital rate estimates calculated using relatively small data sets that are now more than a decade old. We estimated more current, precise adult and juvenile apparent survival $(\Phi)$ probabilities and their associated variances for male GCWAs. In addition to providing estimates for use in population modeling, we tested hypotheses about spatial and temporal variation in $\Phi$. We assessed whether a linear trend in $\Phi$ or a change in the overall mean $\Phi$ corresponded to an observed increase in GCWA abundance during 1992-2000 and if $\Phi$ varied among study plots. To accomplish these objectives, we analyzed long-term GCWA capture-resight data from 1992 through 2011 , collected across seven study plots on the Fort Hood Military Reservation using a Cormack-Jolly-Seber model structure within program MARK. We also estimated $\Phi$ process and sampling variances using a variance-components approach. Our results did not provide evidence of site-specific variation in adult $\Phi$ on the installation. Because of a lack of data, we could not assess whether juvenile $\Phi$ varied spatially. We did not detect a strong temporal association between GCWA abundance and $\Phi$. Mean estimates of $\Phi$ for adult and juvenile male GCWAs for all years analyzed were 0.47 with a process variance of 0.0120 and a sampling variance of 0.0113 and 0.28 with a process variance of 0.0076 and a sampling variance of 0.0149 , respectively. Although juvenile $\Phi$ did not differ greatly from previous estimates, our adult $\Phi$ estimate suggests previous GCWA population models were overly optimistic with respect to adult survival. These updated $\Phi$ probabilities and their associated variances will be incorporated into new population models to assist with GCWA conservation decision making.
\end{abstract}

\section{Survie en fonction de l'âge des Parulines à dos noir mâles sur la réserve militaire de Fort Hood, Texas}

RÉSUMÉ. Les modèles de population sont des éléments essentiels des plans de gestion et de conservation à grande échelle pour la Paruline à dos noir (Setophaga chrysoparia; abrégée PADN ci-dessous), désignée « menacée » par le gouvernement fédéral étatsunien. Toutefois, les modèles existants sont fondés sur des estimations de taux vitaux calculées à partir d'échantillons relativement petits qui datent maintenant de plus d'une décennie. Nous avons actualisé et précisé la probabilité de survie apparente $(\Phi)$ adulte et juvénile et calculé les variances associées pour les mâles PADN. En plus de ces estimations destinées à la modélisation des populations, nous avons testé les hypothèses de variations spatiale et temporelle de $\Phi$. Nous avons évalué si une tendance linéaire de $\Phi$ ou un changement de $\Phi$ moyen correspondait à une augmentation réelle du nombre de PADN de 1992 à 2000, et si $\Phi$ avait varié entre les parcelles échantillonnées. Pour atteindre nos objectifs, nous avons analysé les données de capture-réobservation de PADN de 1992 à 2011, récoltées dans sept parcelles situées sur la réserve militaire de Fort Hood, Texas, au moyen d'une structure de modèle de Cormack-Jolly-Seber avec le programme MARK. Nous avons aussi estimé les composantes de la variance de $\Phi$ associées au processus et à l'échantillonnage en les partitionnant. Nos résultats n’ont pas confirmé qu'il existait une variation du $\Phi$ adulte propre au site. À cause du petit échantillon de données, nous n'avons pas pu déterminer si le $\Phi$ juvénile avait varié spatialement. Nous n'avons pas détecté d'association temporelle forte entre le nombre de PADN et $\Phi$. L'estimation moyenne de $\Phi$ s'élevait à 0,47 pour les mâles adultes, avec une variance relative au processus de 0,0120 et une variance relative à l'échantillonnage de 0,0113 , et atteignait 0,28 pour les mâles juvéniles, avec une variance relative au processus de 0,0076 et une variance relative à l'échantillonnage de 0,0149 . Alors que notre estimation de $\Phi$ juvénile ne diffère pas grandement des estimations antérieures, notre estimation de $\Phi$ adulte indique que les modèles précédents de population pour la PADN étaient trop optimistes quant à la survie des adultes. Ces probabilités actualisées de $\Phi$ et leurs variances seront incluses dans de nouveaux modèles de population afin de contribuer à la prise de décision touchant la conservation de la PADN.

Key Words: adult survival; capture-resight; Golden-cheeked Warbler; juvenile survival; MARK; process variance; Setophaga chrysoparia; variance components

\section{INTRODUCTION}

The Golden-cheeked Warbler (Setophaga chrysoparia; hereafter GCWA) is a neotropical migrant passerine that breeds almost exclusively in the mature oak-juniper woodlands of central Texas
(Pulich 1976). Motivated by concerns about the GCWA's restricted breeding range and the perceived ongoing loss of breeding habitat, the species was listed as endangered by the U. S. federal government in 1990 (USFWS 1990; R. Wahl, D. D.

Address of Correspondent: Adam Duarte, Department of Biology, Texas State University, 601 University Drive, San Marcos, TX, 78666 USA, ad1401@txstate.edu 
Diamond, and D. Shaw, unpublished manuscript). Following the species' federal listing, a recovery plan was produced that described the species' basic biology and various threats, separated the GCWA's breeding range into eight regions to manage the species' recovery process, and established recovery criteria that must be met before the GCWA can be downlisted (USFWS 1992).

Given that the criteria to downlist the species include "sufficient breeding habitat has been protected to ensure the continued existence of at least one viable, self-sustaining population in each of 8 regions outlined in the plan" (USFWS 1992:iv), it is no surprise that population models are currently being used to assist in GCWA conservation efforts (USFWS 1996, Alldredge et al. 2004, Vaillant et al. 2004, Horne et al. 2011). Natural resource agencies are currently operating under the population viability analysis (PVA) results of Alldredge et al. (2004). Their model suggests that enough good-quality breeding habitat in each of the eight regions with the potential to support a carrying capacity of 3000 breeding pairs is required to ensure a low probability of extinction for GCWAs over the next 100 years. Fortunately, the amount of breeding habitat currently available is well above this threshold, because it supports an estimated 263,339 $(95 \%$ confidence interval $=223,927-302,620)$ male GCWAs across the entire breeding range (Mathewson et al. 2012). However, the current amount of breeding habitat on publicly owned property in each region outlined in the species' recovery plan does not support that many male GCWAs (Hatfield et al. 2012a), and breeding habitat located on privately owned property is not certain to be protected and available in the future (Groce et al. 2010, Duarte et al. 2013).

Fundamental to projecting population dynamics are up-to-date estimates of abundance and vital rates. In the case of territorial songbirds such as the GCWA, females are more difficult to detect than males. Consequently, population parameters are often reported for male birds, and population models focus on the male segment of the species. Previous GCWA PVAs used vital rate estimates that are now more than 10 years old, did not have access to a robust abundance estimate for the initial starting point of abundances at year one of the simulations, did not incorporate geographic variability in reproductive success, and only modeled a portion of the species' breeding range. Thus, a new PVA is warranted and might significantly alter our outlook on GCWA viability. In recent years much effort has been expended to update our knowledge on GCWA abundance and reproduction both at the local and range-wide scale (e.g., abundance, Hunt et al. 2012, Mathewson et al. 2012, Collier et al. 2013, Peak and Thompson 2013, Warren et al. 2013; reproduction, Campomizzi et al. 2012, Klassen et al. 2012, Marshall et al. 2013). Apparent survival ( $\Phi)$ has been estimated for juvenile (hatch year, HY) and adult (after hatch year, AHY) male GCWAs while accounting for imperfect detection in the past, where $\Phi$ is the probability that an individual remains alive and returns to the study area from one sampling occasion to the next. Still, these estimates were derived from studies consisting of only five years of data collected on a single study plot, with the 2001 field season being the most recent data analyzed (USFWS 1996, Alldredge et al. 2004). In the absence of up-to-date robust $\Phi$ estimates, GCWA return rates, i.e., the proportion of marked individuals from one year that are resighted in subsequent years, are often used by resource agencies as an indication of annual survival (Peak and Grigsby 2011, Travis
County 2011). However, return rates do not account for imperfect detection and are notorious for being negatively biased (Martin et al. 1995).

Our aim was to update HY and AHY male GCWA annual $\Phi$ estimates, and their associated variances, using long-term capture-resight data collected on seven plots within the Fort Hood Military Reservation (hereafter Fort Hood) to use in future population models. Unlike previous studies, we had the opportunity to test for spatial variability in GCWA $\Phi$ on the installation. We hypothesized that GCWA $\Phi$ would vary among study plots. Our justification for expecting spatial variability in $\Phi$ was related to differences in emigration rates because of habitat structure within each plot, rather than carryover effects of breeding habitat on annual mortality. That is, individuals might choose to breed in alternate locations in subsequent years if the habitat structure within a given plot was not amenable to successful territories, i.e., territories that fledge young, which could result in spatial differences in $\Phi$ estimates. Furthermore, long-term point-count data collected on the installation suggest a positive trend in GCWA densities from 1992 to 2001, after which the population began to show evidence of stabilization (Fig 3.2 in Peak 2011a). However, pairing success, territory success, nest survival, and return-rate data do not indicate temporal trends (reviewed in Groce et al. 2010). Golden-cheeked Warbler $\Phi$ might be directly related to the observed population dynamics in at least two nonmutually exclusive ways. Apparent survival might be inversely related to abundance because of density dependence. Also, a larger overall mean $\Phi$ during the population increase, followed by a lower mean $\Phi$ during the population stabilization period, might be driving the observed population dynamics. Thus, we tested two hypotheses concerning temporal variability in GCWA $\Phi$ on the installation: (1) a negative linear trend in $\Phi$ corresponds to the observed increase in GCWA densities; and (2) the overall mean $\Phi$ during intervals between 1992 and 2001 was greater than the overall mean $\Phi$ during intervals between 2001 and 2011.

\section{METHODS}

\section{Sampling protocol}

Field work for this study was conducted on Fort Hood, a 87,890hectare contiguous parcel of land located in Bell and Coryell counties, central Texas (Fig. 1). Approximately 21,422 hectares of GCWA breeding habitat are within the boundaries of Fort Hood (Hayden et al. 2001). Baccus et al. (2007) provide a detailed description of the environments on Fort Hood and the protocols used to monitor GCWAs. Briefly, from April to June GCWAs were captured in mist nets using playback recordings of conspecific songs as an attractant. Then age and sex were determined for each bird using methods described by Pyle (1997) and Peak and Lusk (2011). All birds captured were uniquely marked using both U.S. Geological Survey aluminum bands and a distinctive combination of plastic, colored leg bands. Monitoring efforts occurred every five days for at least two hours in an effort to resight birds that were marked in previous years, calculate density estimates via spot mapping, and collect behavioral and reproductive data (Peak 2011b).

From 1991 to 2011, 4035 GCWAs, both male and female birds of different age classes, were marked by various entities under 
Table 1. Years and study plots where Golden-cheeked Warbler (Setophaga chrysoparia) surveys were conducted by the Nature Conservancy and Monitoring Avian Productivity and Survivorship programs on the Fort Hood Military Reservation, Texas, USA. Banding and monitoring efforts were conducted from April through June. Table excludes 1991 because study plots were not delineated until 1992.

\begin{tabular}{|c|c|c|c|c|c|c|c|c|c|c|c|c|c|c|c|c|c|c|c|c|}
\hline \multirow[b]{2}{*}{$\underline{\text { Study Plot }}$} & \multicolumn{20}{|c|}{ Year } \\
\hline & 1992 & 1993 & 1994 & 1995 & 1996 & 1997 & 1998 & 1999 & 2000 & 2001 & 2002 & 2003 & 2004 & 2005 & 2006 & 2007 & 2008 & 2009 & 2010 & 2011 \\
\hline Thirteen B & $\mathrm{X}$ & $\mathrm{X}$ & $\mathrm{X}$ & $\mathrm{X}$ & $\mathrm{X}$ & $\mathrm{X}$ & $\mathrm{X}$ & $\mathrm{X}$ & $\mathrm{X}$ & $\mathrm{X}$ & $\mathrm{X}$ & $\mathrm{X}$ & $\mathrm{X}$ & $\mathrm{X}$ & $\mathrm{X}$ & $\mathrm{X}$ & $\mathrm{X}$ & $\mathrm{X}$ & $\mathrm{X}$ & $\mathrm{X}$ \\
\hline Monitoring Avian & & & & $\mathrm{X}$ & $\mathrm{X}$ & $\mathrm{X}$ & $\mathrm{X}$ & $\mathrm{X}$ & $\mathrm{X}$ & $\mathrm{X}$ & $\mathrm{X}$ & $\mathrm{X}$ & $\mathrm{X}$ & $\mathrm{X}$ & $\mathrm{X}$ & $\mathrm{X}$ & $\mathrm{X}$ & & & \\
\hline \multicolumn{21}{|l|}{ Productivity and } \\
\hline \multicolumn{21}{|l|}{ Survivorship } \\
\hline North West Fort Hood & & & & & & $\mathrm{X}$ & $\mathrm{X}$ & $\mathrm{X}$ & $\mathrm{X}$ & $\mathrm{X}$ & $\mathrm{X}$ & $\mathrm{X}$ & $\mathrm{X}$ & $\mathrm{X}$ & & & & & & \\
\hline South West Fort Hood & & & & & & $\mathrm{X}$ & $\mathrm{X}$ & $\mathrm{X}$ & $\mathrm{X}$ & $\mathrm{X}$ & $\mathrm{X}$ & & & & & & & & & \\
\hline Belton Lake Outdoor & & & & & & & $\mathrm{X}$ & $\mathrm{X}$ & $\mathrm{X}$ & $\mathrm{X}$ & $\mathrm{X}$ & $\mathrm{X}$ & & & & & & & & \\
\hline Recreation Area & & & & & & & & & & & & & & & & & & & & \\
\hline Manning & & & & & & & & & $\mathrm{X}$ & $\mathrm{X}$ & $\mathrm{X}$ & $\mathrm{X}$ & $\mathrm{X}$ & $\mathrm{X}$ & $\mathrm{X}$ & $\mathrm{X}$ & $\mathrm{X}$ & $\mathrm{X}$ & $\mathrm{X}$ & $\mathrm{X}$ \\
\hline South Fort Hood & & & & & & & & & & & & & & & $\mathrm{X}$ & $\mathrm{X}$ & $\mathrm{X}$ & & & \\
\hline
\end{tabular}

Fig. 1. Map of the Fort Hood Military Reservation, Texas, USA, and study plots where Golden-cheeked Warbler (Setophaga chrysoparia) capture-resight programs occurred for at least three years. 13 B is Thirteen B, BLORA is Belton Lake Outdoor Recreation Area, SFH is South Fort Hood, M is Manning, NWFH is North West Fort Hood, SWFH is South West Fort Hood, and MAPS is Monitoring Avian Productivity and Survivorship.

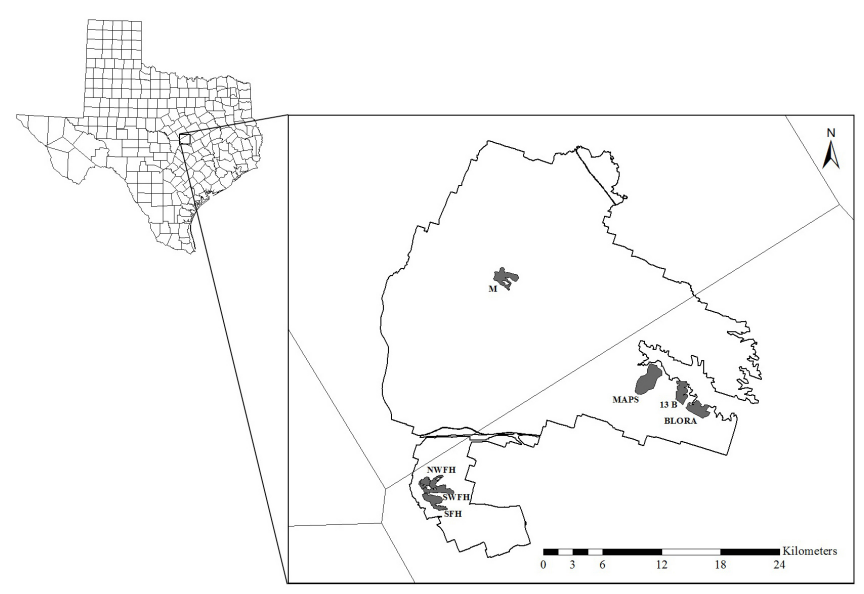

different programs to achieve several objectives. However, a minimum of three years of capture-resight data are needed to calculate one estimate of $\Phi$ using a fully time-specific model (Pollock et al. 1990), and only the Nature Conservancy, in collaboration with Fort Hood, and the Monitoring Avian Productivity and Survivorship programs surveyed the same plots for at least three years (R. Peak, U.S. Army Garrison-Fort Hood, Directorate of Public Works, personal communication). Although the Nature Conservancy program initiated GCWA captureresight efforts on Fort Hood in 1991, the program did not delineate any study plots until 1992. Since 1992, the Nature Conservancy program has delineated six study plots to monitor GCWA population parameters. However, surveys were not conducted on all plots across the entire time series. The Monitoring Avian Productivity and Survivorship program was initiated on Fort Hood in 1995 and conducted annual surveys for marked birds in the same plot through the 2008 breeding season. Thus, we used capture-resight data from the seven study plots that were monitored by these two programs for at least three years (Table 1). Notably, once a study plot was established it was surveyed annually until monitoring ceased on that particular plot; that is, sampling intervals were all one year.

\section{Survival analyses}

A Cormack-Jolly-Seber model structure was used to estimate $\Phi$ (Cormack 1964, Jolly 1965, Seber 1965) with the age-specific extension of Pollock (1981) for HY birds. During preliminary analyses we determined that six of the seven study plots had an insufficient number of HY captures and subsequent resightings. The exception was study plot Thirteen B. Consequently, two separate analyses were conducted to estimate HY and AHY Ф.

The AHY $\Phi$ analysis included capture-resight data from 1434 AHY male GCWAs captured from 1992 to 2011 on seven study plots. These data were insufficient to accommodate interaction terms when modeling sources of variation. Consequently, we began by fitting a model where $\Phi$ and resight probability $(p)$ both varied as a function of the additive effects of study plot and time $($ model $s p+t)$. We then fit a series of models in which $\Phi$ and $p$ varied among study plots (model $s p$ ), over time (model $t$ ), or neither (model .). Further, we used the basic structure of the bestsupported model and constrained $\Phi$ to be constant across years for two sets of years; i.e., we included a separate $\beta$ parameter to test for differences in $\Phi$ during intervals between 1992-2001 and 2001-2011 (model dif). If there was a difference in mean $\Phi$ during the two intervals, the separate $\beta$ parameter would be different than zero. We did not test for linear trends in $\Phi$ for this analysis because of the inconsistencies in years in which study plots were monitored. For all AHY models, resight probabilities were constrained to zero for years in which a particular study plot was not monitored because there cannot be a resighting of a marked individual in a plot that was not surveyed in a given year.

Because of a lack of data in subsequent years, the HY $\Phi$ analysis only included capture-resight data from $132 \mathrm{HY}$ and $233 \mathrm{AHY}$ 
male GCWAs captured from 1992 to 2000 on study plot Thirteen B. There were insufficient data to estimate one of the HY $\Phi$ parameters when fitting a model with an interaction term between age and time. Thus, we began by fitting a model where $\Phi$ varied with age and time additively (model $a+t)$ and $p$ varied across time (model $t)$. We then fit models where $\Phi$ varied with age (model $a$ ), time (model $t$ ), or neither (model .), and also fit models where $p$ was constant (model.). To test for a linear trend in $\Phi$, we used the basic structure of the best-supported model and constrained $\Phi$ to be different between age classes, with $\Phi$ for each age class having a linear trend across time (model $a+T$ ).

A variance-components approach was used to decompose the temporal variance of the $\Phi$ point estimates into components associated with process variance and sampling variance (Burnham and White 2002). It is suggested that this type of analysis be applied to the global model to estimate variance components for $\Phi$ using a model that does not have many constraints. We were interested in estimating a single overall mean $\Phi$ with its associated variances to use in GCWA population models. Consequently, we used an intercept variance-components model. Notably, an intercept model assumes that the underlying $\Phi$ probabilities are distributed randomly around a central mean over time. As suggested, we applied the variance-components approach to the global models for each age-class analysis, i.e., AHY analysis $\Phi_{s p^{*} t}, p_{s p^{*} t}$, and HY analysis $\Phi_{a^{*} t}, p_{t}$. All inestimable parameters were excluded. To make direct comparisons concerning the amount of variability in $\Phi$, we used the mean and process variance $\Phi$ estimates to calculate the coefficient of variation $(\mathrm{CV})$ of $\Phi$ for each age class.

Model selection was based on change in Akaike's Information Criterion corrected for small sample size $\left(\Delta \mathrm{AIC}_{c}\right)$ and $\mathrm{AIC}_{c}$ weights $\left(w_{i}\right)$, such that the best-supported model had a value of zero for $\Delta \mathrm{AIC}_{c}$ and the largest $w_{i}$ (Burnham and Anderson 2002). Using a parametric-bootstrap approach, the goodness of fit of the most general model, i.e., AHY analysis $\Phi_{s p+t}, p_{s p+t}$, and HY analysis $\Phi_{a+t}, p_{t}$, was tested by simulating 1000 data sets, computing the deviance for each, and then comparing the observed deviance with the distribution of deviances from the bootstrap to estimate the probability of observing a deviance as extreme as we did. If there was evidence of a lack of fit, a varianceinflation factor $(\hat{c})$ was estimated by dividing the observed deviance by the average simulated deviance. All analyses were conducted using program MARK (White and Burnham 1999).

After completing the process of initial model selection, we decided to investigate the potential importance of a phenomenon that was not incorporated into the original model set for AHY birds. One possible cause of spatial variability in $\Phi$, i.e., individuals might choose to breed in alternate locations in subsequent years, implies that transient individuals might be prevalent. However, individuals might be choosing to breed in alternate locations in subsequent years at the same rate across study plots. To test this possibility, we used the basic structure of the model in the original model set that was best supported and set apparent survival in the first interval after initial capture $\left(\Phi^{l}\right)$ to differ from apparent survival during subsequent intervals ( $\Phi^{2}$; see Pradel et al. 1997), considering three different scenarios: (1) $\Phi^{l}$ was constant across the time series (model $\Phi^{l}, \Phi^{2}{ }_{t}$ ); (2) $\Phi^{l}$ varied across time (model $\Phi^{1}{ }^{1}, \Phi^{2},{ }^{2}$ ); and (3) $\Phi^{l}$ varied across time, but paralleled $\Phi^{2}$ (model $\left.\Phi^{1}{ }_{+t}, \Phi^{2}\right)$.

\section{RESULTS}

A total of 17 models were included in the original candidate model set for the AHY $\Phi$ analysis (Table 2). The goodness-of-fit test suggested the most general model did not fit the data well $(P<$ 0.001 ), and $\hat{c}$ was estimated to be 1.25 . The best-supported model in the original candidate model set was model $\Phi_{t}, p_{s p}$. In this model, $\Phi$ varied across time, but did not differ among study plots. Resight probabilities varied among study plots but were constant across time. Estimates of $\Phi$ ranged from 0.25 to 0.75 (Fig. 2), and estimates of $p$ ranged from 0.32 to 1 , depending on the study plot. In the model that tested for temporal differences in the mean $\Phi$, i.e., $\Phi_{d i f}, p_{s p}$, the $\beta$ parameter reflecting the difference between the two periods was estimated at $0.40(95 \%$ confidence interval $=$ $0.19-0.61)$. Thus, this model suggested the mean $\Phi$ during the interval 1992-2001 was $10 \%$ higher than mean $\Phi$ during the interval 2001-2011. However, this model had little support, ranking tenth overall. Using variance components, we estimated that the overall mean \pm SE AHY $\Phi$ was $0.47 \pm 0.02$, with process and sampling variances of 0.0120 and 0.0113 , respectively. The CV for AHY $\Phi$ was 0.23 .

Table 2. Model selection statistics for after-hatch-year male Golden-cheeked Warbler (Setophaga chrysoparia) capture-resight data from seven study plots on the Fort Hood Military Reservation, Texas, USA, 1992-2011. Model selection was corrected for overdispersion and based on change in Akaike's Information Criterion corrected for small sample size ( $\triangle$ QAIC $\left._{c}\right)$ and QAIC $_{\mathrm{c}}$ weights $\left(w_{i}\right)$ such that the best-supported model had the smallest $\Delta$ QAIC $_{\mathrm{c}}$ and the largest $w_{i} . \Phi-$ apparent survival probability, $p$ - resight probability, $s p+t$ - study plot and time, $s p$ - study plot, $t$ - time, . - constant, dif - separate $\beta$ parameter for intervals during 1992-2001.

\begin{tabular}{lcccc}
\hline \hline Model & $\Delta$ QAIC $_{c}$ & $w_{i}$ & $\mathrm{~K}$ & QDev \\
\hline$\Phi_{t}, \mathrm{p}_{s p}$ & 0.00 & 0.87 & 26 & 388.70 \\
$\Phi_{s p+t}, \mathrm{p}_{s p}$ & 4.01 & 0.12 & 32 & 380.37 \\
$\Phi_{t}, \mathrm{p}_{s p+t}$ & 10.12 & 0.01 & 43 & 363.70 \\
$\Phi_{s p+t}, \mathrm{p}$ & 14.56 & 0.00 & 26 & 403.26 \\
$\Phi, \mathrm{p}_{s p+t}$ & 15.04 & 0.00 & 26 & 403.74 \\
$\Phi_{t}, \mathrm{p}, \mathrm{p}_{s p+t}$ & 15.35 & 0.00 & 20 & 416.31 \\
$\Phi_{s p+t}, \mathrm{p}_{s p+t}$ & 17.64 & 0.00 & 49 & 358.69 \\
$\Phi_{s p+t}, \mathrm{p}_{t}$ & 18.01 & 0.00 & 43 & 371.59 \\
$\Phi_{t}, \mathrm{p}_{t}$ & 18.10 & 0.00 & 37 & 384.14 \\
$\Phi_{d i,}, \mathrm{p}_{s p}$ & 18.97 & 0.00 & 9 & 442.24 \\
$\Phi_{.}, \mathrm{p}_{t}$ & 19.82 & 0.00 & 20 & 420.78 \\
$\Phi_{s p}, \mathrm{p}_{t}$ & 20.21 & 0.00 & 26 & 408.91 \\
$\Phi_{s p}, \mathrm{p}_{s p+t}$ & 23.65 & 0.00 & 32 & 400.02 \\
$\Phi_{.}, \mathrm{p}_{s p}$ & 30.75 & 0.00 & 8 & 456.03 \\
$\Phi_{s p}, \mathrm{p}_{s p}$ & 40.58 & 0.00 & 14 & 453.73 \\
$\Phi_{.}, \mathrm{p}_{.}$ & 47.81 & 0.00 & 2 & 485.15 \\
$\Phi_{s p}, \mathrm{p}$ & 49.57 & 0.00 & 8 & 474.86 \\
\hline
\end{tabular}

As described above, we took the basic structure of the low-AIC model for the AHY analysis and added transient parameters in three different ways. The transient model $\left(\Phi^{1}{ }_{+t}, \Phi^{2}{ }_{t}, p_{s p}\right)$ actually had a lower $\mathrm{AIC}_{c}$, by $3.88 \mathrm{AIC}_{c}$ units, than model $\Phi_{t}, p_{s p}$. The transient models dealt with the possibility of transient birds by allowing $\Phi^{1}$ to differ from, i.e., be smaller than, $\Phi^{2}$. However, the a posteriori transient models estimated higher, not lower, $\Phi$ probabilities for individuals that were newly marked; estimates 
were $5 \%$ to $7 \%$ higher. These estimates were not consistent with the existence of transients. We could think of no a posteriori hypothesis for this pattern in $\Phi$ that was biologically relevant, so we based our inferences on the original model set shown in Table 2.

For the HY $\Phi$ analysis, $\Phi$ varied additively between age classes and across time, but $p$ was constant across time (Table 3 ). The goodness-of-fit test suggested that the most general model fit the data $(P=0.11)$. Thus, we assumed $\hat{c}$ was equal to one. Estimated HY $\Phi$ probabilities ranged from 0.17 to 0.46 (Fig. 2). For this analysis, the mean estimated AHY $\Phi$ was 0.54 and estimated $p$ was 0.84 . The model that constrained $\Phi$ to vary linearly across time, i.e., $\Phi_{a+t}, p$, suggested there was a negative linear trend in AHY and HY $\Phi$ probabilities from 1992 to 2000. This model, however, ranked third overall, with a weight of only 0.06 . Using variance components, we estimated that the overall mean $\pm \mathrm{SE}$ HY $\Phi$ was $0.28 \pm 0.06$, with process and sampling variances of 0.0076 and 0.0149 , respectively. The CV for HY $\Phi$ was 0.31 .

Table 3. Model selection statistics for capture-resight data for hatch-year and after-hatch-year male Golden-cheeked Warblers (Setophaga chrysoparia) from study plot Thirteen B, Fort Hood Military Reservation, Texas, USA, 1992-2000. Model selection was based on change in Akaike's Information Criterion corrected for small sample size $\left(\Delta \mathrm{AIC}_{\mathrm{c}}\right)$ and $\mathrm{AIC}_{\mathrm{c}}$ weights $\left(w_{i}\right)$ such that the best-supported model had the smallest $\Delta \mathrm{AIC}_{\mathrm{c}}$ and the largest $w_{i}$. $\Phi$ - apparent survival probability, $p$ - resight probability, $a+t$ - age and time, $a$ - age , $t$ - time, . - constant, $T$ - linear trend.

\begin{tabular}{lcccc}
\hline \hline Model & $\Delta \mathrm{AIC}_{c}$ & $w_{i}$ & $\mathrm{~K}$ & $\mathrm{Dev}$ \\
\hline$\Phi_{a+t}, p$ & 0.00 & 0.78 & 10 & 117.87 \\
$\Phi_{a}, p$ & 3.36 & 0.15 & 3 & 135.62 \\
$\Phi_{a+T}, p$ & 5.21 & 0.06 & 4 & 135.43 \\
$\Phi_{a+t}, p_{t}$ & 8.31 & 0.01 & 16 & 113.52 \\
$\Phi_{a}, p_{t}$ & 12.90 & 0.00 & 10 & 130.77 \\
$\Phi_{t}, p_{.}$ & 22.19 & 0.00 & 2 & 156.46 \\
$\Phi_{t}, p_{t}$ & 30.26 & 0.00 & 15 & 137.60 \\
$\Phi, p_{t}$ & 32.12 & 0.00 & 9 & 152.07 \\
\hline
\end{tabular}

\section{DISCUSSION}

We present, to our knowledge, the first detailed analysis to estimate $\Phi$ for the Golden-cheeked Warbler. Using long-term male GCWA capture-resight data collected within multiple study plots on Fort Hood, we were able to test for spatial and temporal patterns in AHY and HY $\Phi$, and calculate more precise $\Phi$ estimates and their process and sampling variances. We found little evidence linking the observed GCWA population dynamics to temporal patterns in $\Phi$. Nor did we detect spatial variation in $\Phi$. The overall mean HY $\Phi$ estimate did not differ greatly from previous estimates for the species. However, the lower overall mean AHY $\Phi$ estimate reported herein suggests that previous GCWA PVAs might have been overly optimistic with respect to AHY $\Phi$.

A negative linear trend in $\Phi$ from 1992 to 2000 was detected using a model that incorporated a linear trend in the HY analysis, and there was evidence that the mean $\Phi$ during intervals between 1992 and 2001 was higher than the mean $\Phi$ during intervals between
Fig. 2. Annual probabilities of apparent survival for hatch-year (HY-open circles) and after-hatch-year (AHY-solid circles) male Golden-cheeked Warblers (Setophaga chrysoparia) on the Fort Hood Military Reservation, Texas, USA. For AHY birds, apparent survival $(\Phi)$ varied across time, and resight probability $(p)$ differed among study plots $\left(\Phi_{t,} \mathrm{p}_{s p}\right)$. For HY birds, $\Phi$ varied additively between age classes and across time, and $p$ was constant $\left(\Phi_{a+t}, \mathrm{p}\right)$. Error bars are $95 \%$ confidence intervals.

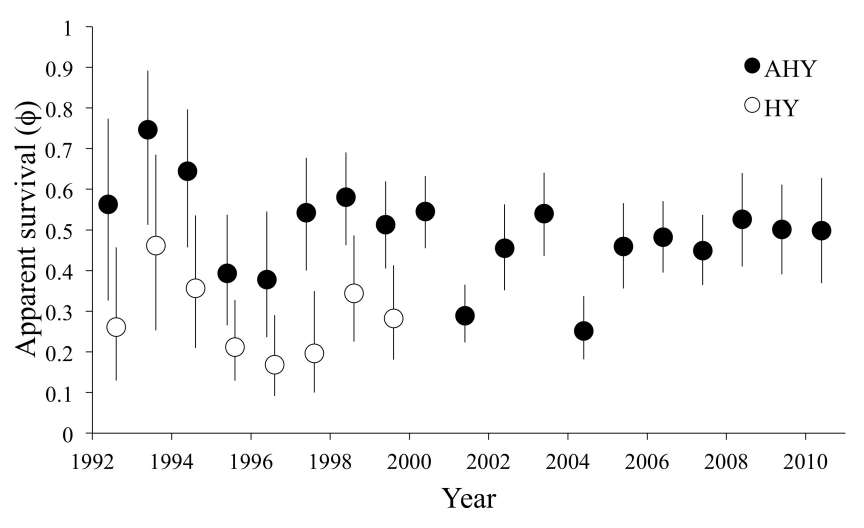

2001 and 2011 in the AHY analysis. Why these patterns emerged is unclear, because these estimates were the product of both true survival and fidelity, which is the complement of permanent emigration. It is possible that as GCWA densities increased on Fort Hood and approached carrying capacity, GCWA dispersal rates increased as available suitable habitat became more limited; that carryover effects from GCWA densities during the breeding season were impacting true survival; or that a change in overall mean $\Phi$ was driving the observed GCWA population dynamics. However, it is also possible that these patterns were a result of a few years with inclement weather conditions during migration that caused $\Phi$ to fluctuate in response to increased mortality (Stokke et al. 2005), and/or caused birds to be blown off course and establish territories in alternate locations. Regardless, these models had little support compared with models with timevarying $\Phi$ that were not constrained to a trend.

We predicted that GCWA $\Phi$ would vary spatially because of potential differences in emigration rates due to habitat structure within each plot. Differences in habitat patch area, landscape composition, i.e., percentage of woodlands within a 400-meter radius, woodland edge, and woodland height have been linked to variation in GCWA occupancy and abundance across Fort Hood (Collier et al. 2013, Farrell et al. 2013, Peak and Thompson 2013), and therefore support this possibility. However, the results provide no evidence that AHY $\Phi$ is site specific. Whether or not HY $\Phi$ varies spatially on Fort Hood is yet to be determined because of insufficient data in this study. These study plots are primarily used to monitor GCWA territory size and density, age structure, mated status, the proportion of territories producing at least one fledgling, and nest survival (Peak and Grigsby 2011). Thus, we suspect that the lack of spatial variability in AHY $\Phi$ was primarily because study plots were selected based on those areas having high densities of GCWAs outside the live-fire training areas, as opposed to randomly selected sites across the installation; 
therefore, they were areas with comparable GCWA habitats. Conversely, the apparent lack of spatial differences in $\Phi$ might be a result of low discriminatory ability of the model selection procedure (the analog of low statistical power to detect a difference; see Morrison et al. 2004). A retrospective overlay of study-plot boundaries and GCWA habitat (as delineated by Diamond et al. 2010) suggests the first possibility might be true. However, fine-scale vegetation cover and height data are not readily available to test these predictions.

Our three models that tested for transient AHY GCWAs provided no evidence that transients were a part of the banded samples. Current observational reports concerning movement of banded GCWAs on Fort Hood support the possibility that there are no, or negligible numbers of, transient AHY GCWAs in these capture-resight data. In the past decade no movement among study plots has been documented, and only two AHY male birds were ever resighted off a study plot. These birds were found immediately outside the study-plot boundary where they were banded in the previous year ( $\mathrm{R}$. Peak, personal communication). However, robust movement data are lacking for the species.

The mean \pm SE annual $\Phi$ for male AHY GCWAs was estimated to be $0.47 \pm 0.02$, which is within the range of annual male AHY $\Phi$ estimates reported for other warbler species such as the Blackthroated Blue Warbler ( $S$. caerulescens) at $0.51 \pm 0.03$ and 0.43 \pm 0.04 (Sillett and Holmes 2002); the American Yellow Warbler (S. petechia) at $0.49 \pm 0.03$ (Climburg et al. 2002) and a mean of 0.48-0.60 (Mazerolle et al. 2005); Swainson's Warbler (Limnothlypis swainsonii) at a mean of $\sim 0.30-0.80$ depending on body condition (Bensen and Bednarz 2010); the Prothonotary Warbler (Protonotaria citrea) at $0.44 \pm 0.07$ (Calvert et al. 2010); and the Blackburnian ( $S$. fusca) and Black-throated Green Warblers (S. virens) at $0.48 \pm 0.09$ (Zitske et al. 2011). However, our AHY $\Phi$ estimate was $16 \%$ lower than what was reported for this species in previous $\Phi$ analyses. USFWS (1996) analyzed capture-resight data collected by the Nature Conservancy program from 1991 to 1995, and reported a mean AHY $\Phi$ estimate of 0.57 . We chose to omit data collected in 1991 because studyplot boundaries were not established until 1992. Thus, individuals captured in 1991 had little to no chance of being resighted in subsequent years (R. Peak, personal communication). We estimated the mean AHY $\Phi$ from 1992 to 1995 as 0.65 . Alldredge et al. (2004) reported a mean AHY $\Phi$ of 0.56 when analyzing capture-resight data collected on Fort Hood from 1997 to 2001. We estimated a mean AHY $\Phi$ of 0.55 for the same interval, i.e., 1997 to 2001 . The differences in $\Phi$ estimates were likely because we excluded data from 1991 when comparing our estimates with those of USFWS (1996) and because we included data from different study plots across a greater number of years.

Because of a lack of capture-resight data, HY $\Phi$ probabilities for recent years could not be estimated. Both USFWS (1996) and Alldredge et al. (2004) estimated a mean HY $\Phi$ of 0.30 when analyzing GCWA capture-resight data from the identical study plot as that for the data used in our analysis, i.e., Thirteen B. The only difference in the time frame in which the data were collected for this analysis is that we chose to omit data from 1991 and 2001 for reasons described earlier and included data from 1996. Thus, it is not surprising that our estimated HY $\Phi$ is no different than previous HY $\Phi$ estimates when taking into account the approximate $95 \%$ confidence interval, i.e., the SE of \pm 0.06 . All three of these HY $\Phi$ estimates are well above the HY $\Phi$ mean \pm SE estimates reported for Prothonotary Warblers, which are 0.06 \pm 0.01 and $0.11 \pm 0.01$, with and without cowbird nestmates, respectively (McKim-Louder et al. 2013). However, $\Phi$ estimates are not directly comparable between studies. McKim-Louder et al. (2013) banded young in nest boxes before fledging occurred and had both males and females in their analysis, and $\Phi$ for HY birds can be related to an assortment of factors including differences in dispersal patterns among species and/or subpopulations. We currently do not have the data to assess whether the relatively high HY GCWA $\Phi$ estimates are an artifact of the individual study plot, are an outcome of the sampling protocol used to band individuals, or are reasonable for this particular species.

The temporal variance of the $\Phi$ point estimates consists of both process and sampling components. Process variance is the true temporal variance in underlying $\Phi$ probabilities. On the other hand, sampling variance is a measure of the uncertainty in the estimates of $\Phi$ that can be attributed to the sampling process and the inability to capture and detect all animals at all occasions. When the temporal variance of the $\Phi$ point estimates is not decomposed into process and sampling variance components, the perceived variability in $\Phi$ over time is positively biased as an estimate of process variance, which will artificially increase the risk of extinction for species if incorporated directly into PVAs (Gould and Nichols 1998). Further, incorporating both process and sampling variances into PVAs in an appropriate manner might have a significant impact on projected population dynamics and, by extension, considerably alter conservation decision making (McGowan et al. 2011). Thus, although these $\Phi$ variances, i.e., process and sampling variance, are often not reported, these estimates are critical for projecting population dynamics of any species. Herein, sampling variance accounted for $48.5 \%$ of the total variance of AHY $\Phi$ and $66.2 \%$ of the total variance of $\mathrm{HY}$ $\Phi$, which illustrates the importance of partitioning the total variance into process and sampling components to gain a better understanding of population dynamics. Our CV estimates indicated that HY $\Phi$ had a greater year-to-year variation than AHY $\Phi$. This finding is consistent with the conclusions of Gould and Nichols (1998) when they investigated age-specific differences in temporal variability of Mallard Duck (Anas platyrhynchos) $\Phi$. This pattern might be coupled with the experience and/or learned behavior of AHY birds, allowing AHY birds to better compensate during adverse environmental conditions and reduce the year-toyear variation in $\Phi$ (Gould and Nichols 1998). We analyzed longer-term capture-resight data than both USFWS (1996) and Alldredge et al. (2004), which should result in more precise estimates of variance. However, our estimate of process variance for AHY $\Phi$ was 0.0120 , which is no different than the value of 0.0119 that was calculated by USFWS (1996). Both these estimates are larger than the value of 0.007 that was calculated by Alldredge et al. (2004). Conversely, our estimate of process variance for HY $\Phi, 0.0076$, is substantially smaller than the value of 0.058 that was calculated by Alldredge et al. (2004).

\section{CONSERVATION IMPLICATIONS}

The population parameter estimates calculated herein will be used in future Golden-cheeked Warbler population models to aid in 
Avian Conservation and Ecology 9(2): 4

http://www.ace-eco.org/vol9/iss2/art4/

large-scale conservation decision making. Given current estimates of vital rates, however, GCWA abundance should be declining dramatically, a scenario that is not supported by the current survey data. This suggests that GCWA movement might be widespread, causing $\Phi$ estimates to be biased low because of permanent emigration. Thus, the use of contemporary hierarchical models to estimate GCWA movement parameters is a fruitful area for further study. It can be approached in at least two ways. If the within-season GCWA location data were available, for instance, it would be beneficial to reformat the data analyzed herein to match a robustdesign sampling framework and use a spatial Cormack-Jolly-Seber model structure (Royle et al. 2014). Open population spatial capture-recapture models allow for the estimation of $\Phi$ during primary sampling periods and density for each trapping session, or in this case each GCWA breeding season, but have the added benefit of being able to explicitly model and estimate dispersal parameters as long as the scale of dispersal is not substantially greater than the scale of the study area. Further, by explicitly incorporating movement information within the analysis, these models have increased precision and accuracy in the derived $\Phi$ estimates (Ergon and Gardner 2013). Another possibility is to combine the captureresight data analyzed herein with ancillary GCWA population data within an integrated population model (Besbeas et al. 2002, Brooks et al. 2004, Schaub and Abadi 2011). By combining the likelihoods of multiple data sets, integrated population models allow for the estimation of population parameters for which few or no explicit data are available, including immigration rates (Abadi et al. 2010). It is worth noting that these two approaches can be combined within a single analysis using a Bayesian approach. Until movement parameters are better understood for the species, however, the direct estimation of population growth rate $(\lambda)$ using capture-resight data (see Pradel 1996, Nichols and Hines 2002) or state-space models (see de Valpine and Hastings 2002, Hatfield et al. 2012b) might be a more effective strategy to assess the viability of individual GCWA subpopulations than use of projection matrices with vital rate estimates.

If population models are used to better understand GCWA population dynamics, it should be noted that there is an inherent limitation to using these $\Phi$ estimates within models that simulate population dynamics at the range-wide scale. Apparent survival on Fort Hood might not accurately represent $\Phi$ across the species' breeding range. The Balcones Canyonlands Preserve, located in Travis County, initiated a GCWA capture-resight program in 2009 (City of Austin 2012). Those data will provide the first estimates of GCWA $\Phi$ off Fort Hood. Still, capture-resight data to estimate $\Phi$ in the southwest and northern portions of the species' breeding range are lacking and, to our knowledge, no such study has been initiated. It is essential we understand how population parameters vary across multiple ecoregions and under different management scenarios to model and conserve range-wide populations more effectively. Furthermore, it is vital that such studies are initiated as soon as possible, given it might require $10 \Phi$ estimates, i.e., 11 years of capture-resight data, to provide precise variance estimates using the variance-components approach (Burnham and White 2002).

\section{Responses to this article can be read online at:}

http://www.ace-eco.org/issues/responses.php/693

\section{Acknowledgments:}

We are grateful to D. J. Brown, H. A. Mathewson, two anonymous reviewers, and the subject editor for providing comments on a previous draft of the manuscript. This project was funded by the U.S. Fish and Wildlife Service through the U.S. Geological Survey Science Support Partnership Program, Texas State University, the Houston Safari Club, and the National Wild Turkey Foundation. R. G. Peak provided information concerning the protocols used to monitor Golden-cheeked Warblers. Any use of trade, product, or firm names is for descriptive purposes only and does not imply endorsement by the U.S. government. This project was sponsored in part by the Department of the Army, U.S. Army Garrison-Fort Hood, Directorate of Public Works, Environmental Division, Natural and Cultural Resources Management Branch (NRMB). The content of the information does not necessarily reflect the position or the policy of the NRMB, and no official endorsement should be inferred.

\section{LITERATURE CITED}

Abadi, F., O. Gimenez, B. Ullrich, R. Arlettaz, and M. Schaub. 2010. Estimation of immigration rate using integrated population models. Journal of Applied Ecology 47:393-400. http://dx.doi. org/10.1111/j.1365-2664.2010.01789.x

Alldredge, M. W., J. S. Hatfield, D. D. Diamond, and C. D. True. 2004. Golden-cheeked Warbler (Dendroica chrysoparia) in Texas: importance of dispersal toward persistence in a metapopulation. Pages 372-383 in H. R. Akçakaya, M. A. Burgman, O. Kindvall, C. C. Wood, P. Sjögren-Gulve, J. S. Hatfield, and M. A. McCarthy, editors. Species conservation and management: case studies. Oxford University Press, New York, New York, USA.

Baccus, J. T., M. E. Tolle, and J. D. Cornelius. 2007. Response of Golden-cheeked Warblers (Dendroica chrysoparia) to wildfires at Fort Hood, Texas. Texas Ornithological Society, Occasional Publication 7:1-37.

Benson, T. J., and J. C. Bednarz. 2010. Relationships among survival, body condition, and habitat of breeding Swainson's Warblers. Condor 112:138-148. http://dx.doi.org/10.1525/cond.2010.080089

Besbeas. P., S. N. Freeman, B. J. T. Morgan, and E. A. Catchpole. 2002. Integrating mark-recapture-recovery and census data to estimate animal abundance and demographic parameters. Biometrics 58:540-547. http://dx.doi.org/10.1111/j.0006-341X.2002.00540. $\mathrm{x}$

Brooks, S. P., R. King, and B. J. T. Morgan. 2004. A Bayesian approach to combining animal abundance and demographic data. Animal Biodiversity and Conservation 27:515-529.

Burnham, K. P., and D. R. Anderson. 2002. Model selection and multi-model inference: a practical information-theoretic approach. Second edition. Springer, New York, New York, USA.

Burnham, K. P., and G. C. White. 2002. Evaluation of some random effects methodology applicable to bird ringing data. Journal of Applied Statistics 29:245-264. http://dx.doi.org/10.1080/02664760120108755

Calvert, A. M., J. Woodcock, and J. D. McCracken. 2010. Contrasting seasonal survivorship of two migratory songbirds wintering in threatened mangrove forests. Avian Conservation and Ecology 5: 2. [online] URL: http://www.ace-eco.org/vol5/iss1/art2/ 
Campomizzi, A. J., S. L. Farrell, T. M. Mcfarland, H. A. Mathewson, M. L. Morrison, and R. N. Wilkins. 2012. Species conservation at a broad spatial scale: reproductive success of Golden-cheeked Warblers across their breeding range. Wildlife Society Bulletin 36:440-449. http://dx.doi.org/10.1002/wsb.172

Cilimburg, A. B., M. S. Lindberg, J. J. Tewksbury, and S. J. Hejl. 2002. Effects of dispersal on survival probability of adult Yellow Warblers (Dendroica petechia). Auk 119:778-789. http://dx.doi. org/10.1642/0004-8038(2002)119[0778:EODOSP]2.0.CO;2

City of Austin. 2012. City of Austin 2012 Golden cheeked Warbler (Setophaga chrysoparia) monitoring program. Balcones Canyonlands Preserve annual report FY 2011-12. City of Austin Water Utility Wildland Conservation Division, Austin, Texas, USA.

Collier, B. A., S. L. Farrell, A. M. Long, A. J. Campomizzi, K. B. Hays, J. L. Laake, M. L. Morrison, and R. N. Wilkins. 2013. Modeling spatially explicit densities of endangered avian species in a heterogeneous landscape. Auk 130:1-11. http://dx.doi. org/10.1525/auk.2013.13017

Cormack, R. M. 1964. Estimates of survival from the sighting of marked animals. Biometrika 51:429-438. http://dx.doi.org/10.2307/2334149

de Valpine, P., and A. Hastings. 2002. Fitting population models incorporating process noise and observer error. Ecological Monographs 72:57-76. http://dx.doi.org/10.1890/0012-9615(2002) 072[0057:FPMIPN]2.0.CO;2

Diamond, D. D., L. F. Elliott, C. Blodgett, C. D. True, D. German, and A. Treuer-Kuehn. 2010. Texas ecological systems classification. Project ID 1/457. Missouri Resource Assessment Partnership. University of Missouri, Columbia, Missouri, and the Texas Parks and Wildlife Department, Austin, Texas, USA. http://morap. missouri.edu/index.php/texas-ecological-systems-classification/

Duarte, A., J. L. R. Jensen, J. S. Hatfield, and F. W. Weckerly. 2013. Spatiotemporal variation in range-wide Golden-cheeked Warbler breeding habitat. Ecosphere 4: 152. http://dx.doi.org/10.1890/ ES13-00229.1

Ergon, T., and B. Gardner. 2013. Separating mortality and emigration: modelling space use, dispersal and survival with robustdesign spatial capture-recapture data. Methods in Ecology and Evolution, early view. http://dx.doi.org/10.1111/2041-210X.12133

Farrell, S. L., B. A. Collier, K. L. Skow, A. M. Long, A. J. Campomizzi, M. L. Morrison, K. B. Hays, and R. N. Wilkins. 2013. Using LiDAR-derived vegetation metrics for high-resolution, species distribution models for conservation planning. Ecosphere 4:42. http://dx.doi.org/10.1890/ES12-000352.1

Groce, J. E., H. A. Mathewson, M. L. Morrison, and N. Wilkins. 2010. Scientific evaluation for the 5-year status review of the Goldencheeked Warbler. Texas A\&M Institute of Renewable Natural Resources, College Station, Texas, USA.

Gould, W. R., and J. D. Nichols. 1998. Estimation of temporal variability of survival in animal populations. Ecology 79:2531-2538. http://dx.doi.org/10.1890/0012-9658(1998)079[2531: EOTVOS]2.0.CO;2

Hatfield, J. S., M. H. Reynolds, N. E. Seavy, and C. M. Krause. 2012b. Population dynamics of Hawaiian seabird colonies vulnerable to sea-level rise. Conservation Biology 26:667-678. http:// dx.doi.org/10.1111/j.1523-1739.2012.01853.x
Hatfield, J. S., F. W. Weckerly, and A. Duarte. 2012a. Shifting foundations and metrics for Golden-cheeked Warbler recovery. Wildlife Society Bulletin 36:415-422. http://dx.doi.org/10.1002/ wsb. 181

Hayden, T. J., H. J. Cornelius, L. L. Weinburg, L. L. Jette, and R. H. Melton. 2001. Endangered species management plan for Fort Hood, Texas; FY01-05. Department of the Army, Engineer Research and Development Center, Construction Engineering Research Laboratory, Champaign, Illinois, USA.

Horne, J. S., K. M. Strickler, and M. Alldredge. 2011. Quantifying the importance of patch specific changes in habitat to metapopulation viability of an endangered songbird. Ecological Applications 21:2478-2486. http://dx.doi.org/10.1890/10-2328.1

Hunt, J. W., F. W. Weckerly, and J. R. Ott. 2012. Reliability of occupancy and binomial mixture models for estimating abundance of Golden-cheeked Warblers (Setophaga chrysoparia). Auk 129:105-114. http://dx.doi.org/10.1525/auk.2012.11093

Jolly, G. M. 1965. Explicit estimates from capture-recapture data with both death and immigration-stochastic model. Biometrika 52:225-247. http://dx.doi.org/10.1093/biomet/52.1-2.225

Klassen, J. A., M. L. Morrison, H. A. Mathewson, G. G. Rosenthal, and R. N. Wilkins. 2012. Canopy characteristics affect reproductive success of Golden-cheeked Warblers. Wildlife Society Bulletin 36:54-60. http://dx.doi.org/10.1002/wsb.100

Martin, T. E., J. Clobert, and D. R. Anderson. 1995. Return rates in studies of life history evolution: are biases large? Journal of Applied Statistics 22:863-875. http://dx.doi.org/10.1080/02664769524676

Marshall, M. E., M. L. Morrison, and R. N. Wilkins. 2013. Tree composition and food availability affect productivity of an endangered species: the Golden-cheeked Warbler. Condor 115:882-892. http://dx.doi.org/10.1525/cond.2013.130013

Mathewson, H. A., J. E. Groce, T. M. Mcfarland, M. L. Morrison, J. C. Newnam, R. T. Snelgrove, B. A. Collier, and R. N. Wilkins. 2012. Estimating breeding season abundance of Golden-cheeked Warblers in Texas, USA. Journal of Wildlife Management 76:1117-1128. http://dx.doi.org/10.1002/jwmg.352

Mazerolle, D. F., K. W. Dufour, K. A. Hobson, and H. E. den Haan. 2005. Effects of large-scale climatic fluctuations on survival and production of young in a neotropical migrant songbird, the Yellow Warbler Dendroica petechia. Journal of Avian Biology 36:155-163. http://dx.doi.org/10.1111/j.0908-8857.2005.03289.x

McGowan, C. P., M. C. Runge, and M. A. Larson. 2011. Incorporating parametric uncertainty into population viability analysis models. Biological Conservation 144:1400-1408. http://dx. doi.org/10.1016/j.biocon.2011.01.005

McKim-Louder, M. I., J. P. Hoover, T. J. Benson, and W. M. Schelsky. 2013. Juvenile survival in a neotropical migratory songbird is lower than expected. PLoS ONE 8:e56059. http://dx. doi.org/10.1371/journal.pone.0056059

Morrison, S. A., D. T. Bolger, and T. S. Sillett. 2004. Annual survivorship of the sedentary Rufous-crowned Sparrow (Aimophila ruficeps): no detectable effects of edge or rainfall in southern California. Auk 121:904-916 http://dx.doi.org/10.1642/0004-8038 (2004)121[0904:ASOTSR]2.0.CO;2 
Nichols, J. D., and J. E. Hines. 2002. Approaches for the direct estimation of $\lambda$ and demographic contributions to $\lambda$, using capturerecapture data. Journal of Applied Statistics 29:539-568. http://dx. doi.org/10.1080/02664760120108809

Peak, R. G. 2011a. Population trends of the Golden-cheeked Warbler on Fort Hood, Texas 1992-2011. In Endangered species monitoring and management at Fort Hood, Texas. 2011 Annual Report. Fort Hood, Directorate of Public Works, Natural Resources Management Branch, Fort Hood, Texas, USA.

Peak, R. G. 2011b. A field test of the distance sampling method using Golden-cheeked Warblers. Journal of Field Ornithology 82:311-319.

Peak, R. G., and N. A. Grigsby. 2011. Golden-cheeked Warbler demography on Fort Hood, Texas, 2011. In Endangered species monitoring and management at Fort Hood, Texas. 2011 Annual Report. Fort Hood, Directorate of Public Works, Natural Resources Management Branch, Fort Hood, Texas, USA.

Peak, R. G., and D. J. Lusk. 2011. Test of the plumage characteristics used to sex Golden-cheeked Warblers in the first basic plumage. North American Bird Bander 36:110-112.

Peak, R. G., and F. R. Thompson, III. 2013. Amount and type of forest cover and edge are important predictors of Golden-cheeked Warbler density. Condor 115:659-668. http://dx.doi.org/10.1525/ cond.2013.120043

Pollock, K. H. 1981. Capture-recapture models allowing for age dependent survival and capture rates. Biometrics 37:521-529. http:// dx.doi.org/10.2307/2530565

Pollock, K. H., J. D. Nichols, C. Brownie, and J. E. Hines. 1990. Statistical inference for capture-recapture experiments. Wildlife Monographs 107:1-97.

Pradel, R. 1996. Utilization of capture-mark-recapture for the study of recruitment and population growth rate. Biometrics 52:703-709. http://dx.doi.org/10.2307/2532908

Pradel, R., J. E. Hines, J.-D. Lebreton, and J. D. Nichols. 1997. Capture-recapture survival models taking account of transients. Biometrics 53:60-72. http://dx.doi.org/10.2307/2533097

Pulich, W. M. 1976. The Golden-cheeked Warbler: a bioecological study. Texas Parks and Wildlife Department, Austin, Texas, USA.

Pyle, P. 1997. Identification guide to North American birds, part I. Slate Creek, Bolinas, California, USA.

Royle, J. A., R. B. Chandler, R. Sollmann, and B. Gardner. 2014. Spatial capture-recapture. Academic Press, Waltham, Massachusetts, USA.

Schaub, M., and F. Abadi. 2011. Integrated population models: a novel analysis framework for deeper insights into population dynamics. Journal of Ornithology 152:227-237. http://dx.doi. org/10.1007/s10336-010-0632-7
Seber, G. A. 1965. A note on the multiple-recapture census. Biometrika 52:249-259. http://dx.doi.org/10.1093/biomet/52.1-2.249

Sillett, T. S., and R. T. Holmes. 2002. Variation in survivorship of a migratory songbird throughout its annual cycle. Journal of Animal Ecology 71:296-308. http://dx.doi.org/10.1046/j.1365-2656.2002.00599. $\mathrm{x}$

Stokke, B. G., A. P. Møller, B.-E. Sæther, G. Rheinwald, and H. Gutscher. 2005. Weather in the breeding area and during migration affects the demography of small long-distance passerine migrant. Auk 122:637-647. http://dx.doi.org/10.1642/0004-8038(2005)122 [0637:WITBAA]2.0.CO;2

Travis County. 2011. Monitoring of the Golden-cheeked Warbler (Setophaga chrysoparia) on Travis County's Balcones Canyonlands Preserve. Travis County Parks and Preserves, Austin, Texas, USA.

U.S. Fish and Wildlife Service (USFWS). 1990. Endangered and threatened wildlife and plants; final rule to list the Golden-cheeked Warbler as endangered. Federal Register 55(87):53153-53160.

U.S. Fish and Wildlife Service (USFWS). 1992. Golden-cheeked warbler (Dendroica chrysoparia) recovery plan. U.S. Fish and Wildlife Service, Albuquerque, New Mexico, USA.

U.S. Fish and Wildlife Service (USFWS). 1996. Golden-cheeked warbler population and habitat viability assessment report. Compiled and edited by C. Beardmore, J. Hatfield, and J. Lewis in conjunction with workshop participants. Report of a August 21-24, 1995 workshop arranged by the U.S. Fish and Wildlife Service in partial fulfillment of U.S. National Biological Service grant no. 80333-1423. U.S. Fish and Wildlife Service, Austin, Texas, USA.

Vaillant, H., H. R. Akcakaya, D. Diamond, and D. True. 2004. Modeling the effects of habitat loss and fragmentation on the Goldencheeked Warbler. Final report, submitted to the Engineering Research and Development Center, Construction Engineering Research Laboratory. Engineering Research and Development Center, Construction Engineering Research Laboratory, Champaign, Illinois, USA.

Warren, C. C., J. A. Veech, F. W. Weckerly, L. O'Donnell, and J. R. Ott. 2013. Detection heterogeneity and abundance estimation in populations of Golden-cheeked Warblers (Setophaga chrysoparia). Auk 130:677-688. http://dx.doi.org/10.1525/auk.2013.13022

White, G. C., and K. P. Burnham. 1999. Program MARK: survival estimation from populations of marked animals. Bird Study 46 (suppl 1):S120-S139. http://dx.doi.org/10.1080/00063659909477239

Zitske, B. P., M. G. Betts, and A. W. Diamond. 2011. Negative effects of habitat loss on survival of migrant warblers in a forest mosaic. Conservation Biology 25:993-1001. http://dx.doi. org/10.1111/j.1523-1739.2011.01709.x
Editor-in-Chief: Ryan Norris Subject Editor: John R.Sauer
Sponsored by the Society of Canadian Ornithologists and Bird Studies Canada Parrainée par la Société des ornithologistes du Canada et Études d'oiseaux Canada

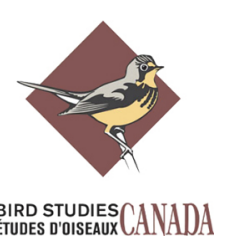

